\title{
Progress and Reflection on the Research of Curriculum and Teaching Theory under the Background of Internet
}

\author{
Li Ruichao \\ Xi’an Fanyi University, Xi’an, Shaanxi, China, 710105
}

Keywords: teaching methodology; curriculum and teaching theory; Internet

\begin{abstract}
The development of Internet technology has brought important influence on the theory and practice of curriculum and teaching theory, which requires the establishment of a new system of curriculum and teaching theory. This paper analyzes the research status quo of socialist core values, curriculum construction, curriculum construction of informatization courses, and curriculum practice, as well as the research status of analyzing teaching models, teaching evaluation and teaching practice. Finally, it analyzes the problems and development trends of the curriculum and teaching theory research, and gives specific recommendations.
\end{abstract}

\section{Introduction}

Curriculum and teaching theory is a unique knowledge system and discipline that occupies an important position in the social science system and teaching [1]. With the rapid development of the Internet age, on the one hand, the theoretical structure of curriculum and teaching theory has developed relatively mature. On the other hand, its research is also facing the challenge of the times. Therefore, it is of great significance to study and reflect on its development in the context of the Internet. At present, the new focus of curriculum and teaching theory is on value education. Therefore, more and more research is focused on the combination of education and values. In addition, the curriculum and education theory also gradually focus on practical issues and the cultivation of students' core qualities. With the development of Internet technology, it brings important changes in curriculum teaching. Therefore, how to establish effective integration with information technology is the current research focus.

\section{The Research Status of Curriculum}

\subsection{Core value construction.}

At present, with the deepening of the reform of our country's society, the concept of socialist core values has been put forward. Therefore, many schools' courses and teaching also aim at developing and nurturing socialist core values. There are also schools and scholars who believe that based on the students' personal characteristics and growth patterns, they should incorporate values of values into teaching practice and establish an integrated education path and model.

\subsection{Curriculum construction.}

Curriculum construction is a systematic project aimed at improving the curriculum system. It is committed to integrating curriculum resources and coordinating curriculum structure, content and implementation methods. At present, the construction of curriculum systems in some localities has achieved certain results, but there are still problems. It is mainly manifested in the failure to well coordinate the relationship between the whole and the local, inside and outside, and between the external and the internal, failing to break through the design difficulties of educating people, teaching philosophy and curriculum structure [2]. Therefore, it is necessary to take students as the foothold for curriculum construction, establish the organic structure of schools, students and disciplines, and pay attention to the logical relationship between knowledge and disciplines. Other schools have studied the relationship between curriculum execution power and curriculum power, trained students' 
knowledge colleagues, and developed their core qualities.

\subsection{Informationization course resources construction.}

The promotion of Internet technology has prompted more and more application of Internet technology in curriculum construction and planning of curriculum resource construction by analyzing user usage data. The application of Internet technology can help solve the problem of uneven distribution of education resources, but it requires students to have a higher self-learning ability. With the aid of Internet technology, the application of multimedia has become more and more popular, bringing vivid and vivid teaching content, which will help improve students' knowledge. On the other hand, the effective integration of internet technology and curriculum resources has also become one of the directions for curriculum and teaching theories. Fully tap and integrate the functions of Internet technology and multimedia, and promote the construction and application of online open courses. The resource structure model provides powerful theoretical support and practical guidance for the construction and development of online open courses.

\subsection{Curriculum practice construction.}

The curriculum practice refers to the school's determination of the organizational form of student research activities, fully mobilizes and exerts the enthusiasm and initiative of student research, and guides students to complete their learning tasks. It also guides students to correctly choose the content and mode of implementation of the research topic, and solves each student's appropriate evaluation of inquiry learning activities.

\section{The Research Status of Teaching Methodology}

\subsection{Teaching model.}

The study of teaching mode should be based on the critical reflection on the traditional teaching model, and based on the information background to construct a new type of teaching model. The teaching model must first focus on the theoretical study of teaching models in order to promote the reform of teaching models and the diversification of teaching schools. In addition, it should pay attention to students' understanding of scientific practice activities. Through reflection, a clear and scientific teaching of nature is conducted to cultivate students' functional scientific literacy. In the context of the Internet, it is necessary to persist in innovation and promote the results of the discipline. For example, there are emerging new models of teaching, which place more emphasis on the student's dominant position and regard students as the core of teaching.

\subsection{Teaching paradigm.}

Teaching paradigm research should reflect on the teaching research process and teaching life, in order to adjust the research direction and methods, improve and transform the teaching life, and unify the theory and practice. At present, there have been several changes in the subject of teaching research, that is, a shift from a single theoretical study to a study of the cooperation between theory and practice. Second is the center of gravity of the research object was changed from teaching to learning. And research methods have shifted from traditional classroom observation methods to qualitative and quantitative research methods. At present, the study of classroom teaching in China is still based on the traditional research paradigm. With the development of Internet technology, with the application of intelligent technology, the learning expertise has been fully utilized. China is also forming a new research paradigm, which not only provides a new foundation for understanding and design learning, but also a new turn in the paradigm of instructional design.

\subsection{Teaching evaluation.}

In the traditional assessment, teacher evaluation completely occupied the dominant position of classroom assessment. As an important means to promote the professional development of teachers and successfully achieve the goals of educating people, the evaluation of classroom-based learning 
can establish the main position of students and promote students' independent learning. On the other hand, classroom assessment can also be used as a special learning value activity and explain the value theory of the emerging textbook assessment. To solve the function of teaching evaluation to promote teacher development, we must change the status quo of teaching behavior or student performance as the object of evaluation. It could improve the learning model for all students by establishing improved teaching and learning for teachers and students.

\subsection{Teaching practice.}

Traditional cognitive science is not conducive to classroom teaching and is not conducive to the overall development of students. The effective teaching practice needs to have a clear teaching goal orientation and a comprehensive teaching plan design, meaning to cultivate students' core qualities. And can use a variety of teaching strategies to present the appropriate teaching content and the introduction of appropriate teaching techniques, and timely feedback on teaching information.

\section{The Problems and Trends in the Research of Curriculum and Teaching Theory}

\subsection{The research paradigm of curriculum and teaching theory needs to be upgraded.}

Traditional curriculum and teaching theory hopes to establish a system that can solve curriculum problems and teaching problems. However, this kind of thinking through the use of research methods such as the nature of basic problems, as well as the use of other disciplines in the theory and methods to study the traditional curriculum and teaching theory cannot solve the problem of constantly changing curriculum and teaching practice [3]. The traditional research paradigm lacks concepts that reflect the characteristics of disciplines, and cannot form a unified logical structure, resulting in chaos in the subject system of curriculum and instructional theory, and it also raises long-term doubts about its legitimacy. In the current context of the Internet, the research of curriculum and teaching theory should be based on the existing curriculum and teaching issues, and lead the development of teaching practice through innovative theoretical results. Constructing a new discipline system of modern curriculum and teaching theory to solve basic theoretical problems. In addition, the development of curriculum and teaching theory needs to continue to draw valuable ideological resources and advanced experience in order to promote the transformation of the subject and research paradigm of curriculum and pedagogy. Therefore, the future trend of curriculum and teaching theory will focus on induction and research, and enhance the practicality of curriculum and pedagogy, study the problems of curriculum and teaching practice under the background of information technology, so as to improve the subject function of curriculum and teaching theory.

\subsection{The research of curriculum and teaching requires team cooperation.}

The current curriculum and teaching research either lacks the necessary teamwork within or between disciplines. This is not conducive to the solution of problems in curriculum and teaching practice, and is not conducive to the formation of theoretical construction. In the context of the Internet, only through the joint efforts of teams can we fundamentally solve the problem of the change of learning methods, thus promoting the development of the modern curriculum and pedagogical discipline system. Internet-based modern teaching technology not only promotes the innovation of teaching methods, but also changes the way of teaching evaluation and management. Therefore, it has become an indispensable and important tool for teachers' daily teaching. However, at the same time, it also requires the systematic thinking of the whole concept of curriculum and teaching theory, and based on the cognitive characteristics of the students in the information background, and studies the integration of information technology and course teaching, so that information technology can better serve the course teaching and the development of students. 


\subsection{The subject system of modern curriculum and teaching theory requires reconstruction.}

In the context of the Internet, the rapid development of information technology has greatly affected people's lives [4]. Therefore, the curriculum and the teaching theory must keep pace with the times, based on the information technology, constantly improve and improve their own theoretical thinking level, so as to build a discipline system with the characteristics of the times. The development of information technology under the background of the Internet breaks the traditional teaching structure and teaching rules, and promotes the transformation of teaching mode and teaching mode. These changes, on the one hand, promote the transformation of students' learning styles and promote the diversification of teaching evaluation methods. On the other hand, it also brings new problems such as the development path and reform mode of curriculum and teaching theory. For example, with the in-depth application of information technology in education and teaching, the limitations of technology have been brought to bear. But how to break through the limitations of technology and maximize the value of technology requires that the thinking of the curriculum and pedagogy researchers should not be limited to the technical level, but based on the teaching purpose and the characteristics of the students, not limited to a specific problem, but from the overall analysis of the promotion of technology to the development of the subject.

\section{Summary}

In the era of Internet, the study of curriculum and teaching theory needs to start with the influence of information technology on teaching theory and teaching practice, in order to establish a new system of curriculum and teaching theory. From the analyzes the current research status of socialist core values, curriculum construction, informatization curriculum resources construction, and curriculum practice, and analyzes research status in teaching models, teaching evaluation, and teaching practice, it can be seen that to realize the healthy development of curriculum and teaching theory research, on the one hand, curriculum and teaching research needs to strengthen teamwork and accelerate the transition of curriculum and teaching paradigm research. On the other hand, it is necessary to rebuild the modern curriculum and pedagogical discipline system so as to adapt to social development and reflect students' learning characteristics.

\section{Acknowledgement}

This is the phased results of Shaanxi cultural tourism corpus research team (number: XFU17KYTDC07), the research project of the Shaanxi Provincial Education Department, "cooperative construction of translation competence in the perspective of constructivism" (number: 16JK2064) and the "translation teaching research of constructivist perspective" in the research project of education and teaching reform of Xi' an Fanyi University (number: J17B10) .

\section{References}

[1] Zhao Wei. Curriculum Resource Construction Based on Big Data: Trends, Values, and Directions[J]. Curriculum, Teaching Materials, Teaching Methods, 2015(4), p.47

[2] Liu Jun. Wisdom Classroom: A New Way for School Classroom Development in the Future of the Internet+Era[J]. Electrical Education in China,2017(7), p.13

[3] Wang Jian. Discussion on the Transformation of Teaching Paradigm in China[J]. Herbal Study of Higher Education, 2015 (4), p.20

[4] Li Na. Teaching Innovation and Deep Learning in the Internet Era [J]. Journal of Distance Education, 2016(2), p.78 